\title{
Response of dimethylsulfide (DMS) in the ocean and atmosphere to global warming
}

\author{
S. Kloster, ${ }^{1,2}$ K. D. Six, ${ }^{1}$ J. Feichter, ${ }^{1}$ E. Maier-Reimer, ${ }^{1}$ E. Roeckner, ${ }^{1}$ P. Wetzel, ${ }^{1}$ \\ P. Stier, ${ }^{1,3}$ and M. Esch ${ }^{1}$ \\ Received 7 May 2006; revised 19 March 2007; accepted 10 May 2007; published 25 July 2007.
}

[1] A global coupled ocean-atmosphere modeling system is applied in a transient climate simulation to study the response to global warming of Dimethylsulfide (DMS) in the ocean, the DMS flux to the atmosphere, and the resulting DMS concentrations in the atmosphere. The DMS production and consumption processes in the ocean are linked to plankton dynamics simulated in the marine biogeochemistry model HAMOCC5.1, embedded in an ocean general circulation model (MPI-OM). The atmospheric model ECHAM5 is extended by the microphysical aerosol model HAM, treating the sulfur chemistry in the atmosphere and the evolution of microphysically interacting internally and externally mixed aerosol populations. For future conditions $(2000-2100)$ we assume greenhouse gas concentrations, aerosol and aerosol precursor emissions according to the SRES A1B scenario. We analyzed the results in terms of simulated changes between the period 1861-1890 and 2061-2090. For the global annual mean DMS sea surface concentration and the DMS flux we found a reduction by $10 \%$. The DMS burden in the atmosphere is reduced by only 3\%, owing to a longer lifetime of DMS in the atmosphere in a warmer climate $(+7 \%)$. Regionally the response and the underlying mechanisms are quite inhomogeneous. The largest reduction in the DMS sea surface concentration is simulated in the Southern Ocean $(-40 \%)$ caused by an increase in the summer mixed layer depth, leading to less favorable light conditions for phytoplankton growth. In the mid and low latitudes DMS sea surface concentrations are predominantly reduced due to nutrient limitation of the phytoplankton growth through higher ocean stratification and less transport of nutrients into the surface layers.

Citation: Kloster, S., K. D. Six, J. Feichter, E. Maier-Reimer, E. Roeckner, P. Wetzel, P. Stier, and M. Esch (2007), Response of dimethylsulfide (DMS) in the ocean and atmosphere to global warming, J. Geophys. Res., 112, G03005, doi:10.1029/2006JG000224.

\section{Introduction}

[2] Increasing atmospheric concentrations of greenhouse gases and aerosols from anthropogenic and natural sources have the potential to induce substantial changes in the climate system [IPCC, 2001]. Climate models predict an accelerated increase of the Earth's mean temperature when greenhouse gas emissions are unabatedly continued. The oceanic response to global warming includes increasing sea surface temperatures, retreat of sea ice, and a general increase of ocean stratification [e.g., Manabe, 1998; Sarmiento et al., 2004]. It is very likely that such changes impact upon the marine biology [Denman et al., 1996; Cox et al., 2000; Bopp et al., 2001; Boyd and Doney, 2002b; Sarmiento et al., 2004]. The response of marine productivity to global warming has been assessed in several studies

\footnotetext{
${ }^{1}$ Max Planck Institute for Meteorology, Hamburg, Germany.

${ }^{2}$ Now at European Commission, DG Joint Research Centre, Institute for Environment and Sustainability, Ispra, Italy.

${ }^{3}$ Now at Department of Environmental Science and Engineering, California Institute of Technology, Pasadena, California, USA.

Copyright 2007 by the American Geophysical Union. 0148-0227/07/2006JG000224\$09.00
}

employing biological models of different complexities [Maier-Reimer et al., 1996; Sarmiento and Lequere, 1996; Sarmiento and Hughes, 1999; Joos et al., 1999; Matear and Hirst, 1999; Bopp et al., 2001; Plattner et al., 2001]. Most of these studies focused on changes in the carbon cycle. Subject of little attention until now are changes in the marine biology which will alter the biogeochemical sulfur cycle in the ocean and the emission of dimethylsulfide (DMS) to the atmosphere.

[3] It has been proposed that the marine biogeochemical sulfur cycle could stabilize the Earth's climate against perturbations by exerting a negative feedback on climate [Shaw, 1983; Charlson et al., 1987]. The proposed mechanism involves the production of DMS by phytoplankton in the ocean, its emission to the atmosphere and subsequent oxidation to sulfate aerosols. Sulfate aerosols alter the amount of solar radiation reaching the Earth's surface both directly by scattering solar energy and indirectly by acting as cloud condensation nuclei $(\mathrm{CCN})$, thereby affecting the cloud albedo. The change in cloud albedo results in global temperature and solar radiation perturbations, both potentially affecting the productivity of the marine biosphere and hence the concentration of oceanic DMS. According to this 
hypothesis (often referred to as the CLAW hypothesis) an increase of DMS emission in a warmer climate would raise atmospheric DMS concentrations, which in turn results in a higher formation of sulfate aerosols. If this also increases the number of $\mathrm{CCN}$, it should make clouds brighter, reflecting more sunlight back to space and cooling the Earth. It has not yet been possible to assess the strength of this proposed feedback on a global scale [Gabric et al., 2004] or even to anticipate if global warming will result in an increase or decrease of DMS emissions.

[4] One of the largest challenges in the assessment of the proposed DMS-cloud-albedo effect is to obtain a detailed understanding of the processes that lead to DMS production and degradation in the ocean and DMS emission into the atmosphere under changing climate conditions. Several attempts to relate DMS sea surface concentrations to single marine biology quantities, like chlorophyll concentrations have failed [Kettle et al., 1999]. Simó and Dachs [2002] proposed an algorithm relating DMS sea surface concentrations to chlorophyll concentration and mixed layer depth. Gabric et al. [2004] applied this formulation to predict the changes in the DMS emissions caused by climate change induced warming. The global annual mean DMS flux change was predicted to be $+14 \%$ in a warmer climate equivalent to a tripling of the atmospheric $\mathrm{CO}_{2}$ concentration. Bopp et al. [2003] applied the DMS formulation given by Aumont et al. [2002], which relates DMS sea surface concentrations to the chlorophyll concentrations and to the food web structure of the ecosystem. Performing a transient climate simulation they find a small increase in the global annual mean DMS flux to the atmosphere $(+2 \%)$ with considerable large spatial variability up to the year 2080 (equivalent to an atmospheric $\mathrm{CO}_{2}$ concentration doubling). According to Bopp et al. [2003] changes in net marine primary production, changes in abundance of phytoplankton species and wind intensity cause the simulated changes in the DMS flux. Bopp et al. [2004] introduced these changes of the DMS flux in an atmospheric model with embedded sulfur chemistry and calculated the resulting radiative perturbation. They find a radiative forcing perturbation resulting from DMS induced changes of $-0.05 \mathrm{~W} / \mathrm{m}^{2}$ representing only a small negative feedback to global warming. Gabric et al. [2003] used a regional marine biogeochemistry model in a transient simulation, including a process based algorithm for DMS production and consumption. They show over the Eastern Antartic Southern Ocean an increase in DMS emissions of $25 \%$ until the year corresponding to a $\mathrm{CO}_{2}$ concentration doubling. The increase of the flux was mainly caused by reduced sea ice coverage. However, none of the model studies mentioned above allow changes in the DMS flux directly to feed back to the atmosphere.

[5] In this study, we simulate DMS production and consumption processes in the ocean as part of the marine biogeochemistry model HAMOCC5.1 [Maier-Reimer et al., 2005]. Embedded in a coupled global ocean-atmosphere General Circulation Model (MPI-OM/ECHAM5), HAMOCC5.1 includes a biological production scheme simulating plankton dynamics on a global scale. Considered processes are the DMS production by phytoplankton, DMS consumption by bacteria, photooxidation of DMS into dimethyl sulfoxide (DMSO), and the DMS flux into the atmosphere [Kloster et al., 2006]. The simulated oceanic DMS flux into the atmosphere is passed to the atmosphere model. The atmosphere model includes a sulfur chemistry scheme and a multicomponent aerosol microphysics model which calculate the atmospheric concentrations of DMS, $\mathrm{SO}_{2}$ in-cloud and gas phase oxidation to $\mathrm{SO}_{4}^{2-}$, the distribution of in-cloud formed $\mathrm{SO}_{4}^{2-}$ and the condensation of gas-phase formed $\mathrm{SO}_{4}^{2-}$ on preexisting particles, as well as the formation of $\mathrm{SO}_{4}^{2-}$ particles.

[6] To investigate the impact of a warmer climate on DMS concentrations in the ocean and atmosphere, we force this fully coupled global ocean-atmosphere model with the IPCC SRES A1B scenario for greenhouse gas concentrations, aerosol and aerosol precursor emissions. This paper focuses on the changes in the marine biology and the subsequent changes in the DMS emissions and DMS concentrations in the atmosphere. It is thereby part of the ongoing analysis of the IPCC experiments of the MaxPlanck Institute for Meteorology.

\section{Model and Simulation Setup}

[7] A detailed description of the model components, the simulation setup and the scenario applied for the future climate forcing is given in the auxiliary material. ${ }^{1}$ Here we only briefly summarize the model and simulation setup.

[8] The coupled atmosphere ocean general circulation model used for the transient climate simulation includes the atmospheric general circulation model ECHAM5 [Roeckner et al., 2003] coupled to the ocean general circulation model MPI-OM [Marsland et al., 2003], including submodels for the aerosol microphysics (HAM [Stier et al., 2005]) and the marine biogeochemistry (HAMOCC5.1 [Maier-Reimer et al., 2005]).

[9] The ocean and the atmosphere model are coupled with a time step of one day with the OASIS coupler [Valcke et al., 2003]. The atmospheric model is applied in the T63 resolution and 19 vertical levels up to $10 \mathrm{hPa}$. Physical processes are calculated on a Gaussian grid with a nominal resolution of $1.8^{\circ}$ in longitude and latitude. The ocean model operates on a Arakawa C-Grid with a resolution of $1.5^{\circ}$ at the equator. The poles are centered over Greenland and Antarctica.

[10] The aerosol model HAM treats the major global aerosol compounds: sulfate, black carbon, particulate organic mass, sea salt, and mineral dust. Mineral dust and sea salt emissions are calculated interactively in the model employing the schemes of Tegen et al. [2002] and Schulz et al. [2004], respectively.

[11] The simulation setup is identical to the one described by Roeckner et al. [2006] and Stier et al. [2006] and is therefore only briefly summarized. The simulation is started from a control run using preindustrial conditions (assumed to be equivalent to the 1860 year conditions) for the aerosol and aerosol precursor emissions, well-mixed greenhouse gases and ozone. For the 2000-2100 period emissions according to the SRES A1B storyline are applied. Emissions source strengths, references and further details are given in the auxiliary material.

\footnotetext{
${ }^{1}$ Auxiliary material data sets are available at ftp://ftp.agu.org/apend/jg/ 2006jg000224. Other auxiliary material files are in the HTML.
} 
[12] The offline monthly mean oxidant fields $\left(\mathrm{OH}, \mathrm{H}_{2} \mathrm{O}_{2}\right.$, $\mathrm{NO}_{2}, \mathrm{O}_{3}$ ) needed in the sulfur chemistry scheme are taken from calculations of the MOZART chemical transport model [Horowitz et al., 2003] representative for the year 2000. These fields are kept constant during the simulation period. This probably introduces an error in our simulation, as these concentrations are likely to change under changing climatic conditions and emissions. As a result of the increase in water vapour concentrations in the atmosphere in a warmer climate, chemical transport models show that the tropospheric oxidant concentrations of $\mathrm{OH}, \mathrm{H}_{2} \mathrm{O}_{2}$, and $\mathrm{O}_{3}$ are enhanced [e.g., Johnson et al., 1999; Gauss et al., 2003]. However, these changes are not included in our transient climate simulation. We will discuss the impact of this simplification in more detail in the discussion chapter.

[13] DMS emissions are calculated in the marine biogeochemistry model HAMOCC5.1, which was extended by a parameterization of the DMS cycle in the ocean [Kloster et al., 2006]. In the following the marine biogeochemistry model HAMOCC5.1 and the DMS parameterization are described in more detail.

[14] HAMOCC5.1. includes a simplified plankton dynamic model treating the compartments Nutrients, Phytoplankton, Zooplankton, DOM (dissolved organic matter) and Detritus. It simulates the net primary production of the phytoplankton community as well as the export of dead organic material out of the euphotic zone. There is no explicit separation of phytoplankton types, but the model accounts for production and export of shell material which consists of opaline and calciferous frustales. Thereby it is assumed that opaline producers are dominating the phytoplankton community as long as silicate is available [Lochte et al., 1993]. Silification and calcification rates in the surface layers are adapted in such a way that the resulting export and dissolution of frustales reproduce the observed vertical silicate and alkalinity profiles. It is assumed that the surface ocean is supersaturated with respect to calcium carbonate throughout the simulation period. According to Orr et al. [2005] this assumption is valid at least until 2100 for the relative moderate future scenario A1B applied in our study.

[15] To study the effects of climate induced DMS changes we restrict in a first attempt the marine DMS cycling to relevant first order processes reported in the literature, such as DMS production by phytoplankton degradation and DMS removal by bacterial consumption, photooxidation and air-sea flux. As little is known about the actual turnover rates of DMS in the ocean we applied an optimization technique to adjust the free parameters in the DMS parameterization to match observed DMS concentrations (see more details in Kloster et al. [2006]). We are aware of the strong simplification by e.g. omitting sulphur pathways like conversion to dissolved DMSP (dimethylsulfonium propionate) or DMSO (dimethylsulfoxide) [Kiene et al., 2000], but as for the description of plankton dynamics we favor in a first approach to apply a simplified, but controllable, setup. Despite the limitations, we still consider our approach, which is based on DMS system dynamics, as superior to purely empirical approaches as outlined in Belviso et al. [2004].
[16] We assume that the DMS release into the water column is only based on the degradation of phytoplankton cells [Simó, 2004]. Intracellular sulphur variations stimulated, e.g., by environmental stresses [Sunda et al., 1990] are hereby neglected. HAMOCC5.1 simulates only the carbon turnover of the phytoplankton community; however, it is known that the intracellular sulphur to carbon ratio considerably differs between phytoplankton groups [Keller et al., 1989]. The simulated export of opaline and calciferous shells gives us an indication of the spatiotemporal changes in the phytoplankton community and can be used as a potential measure for DMS production. The DMS production is formulated as follows:

$$
D M S_{\text {prod }}=f(T) *\left(k_{p s i} * \text { export }_{s i l}+k_{p c c} * \operatorname{export}_{\mathrm{CaCO}_{3}}\right)
$$

where export sil $_{\text {and }}$ export $\mathrm{CaCO}_{3}$ describe the local export of shell material with the largest contribution resulting from phytoplankton degradation. $k_{p s i}$ and $k_{p c c}$ are the respective scaling factors. They implicitly represent a suite of processes e.g. the intracellular $\mathrm{C}: \mathrm{S}$ ratio, bacterial conversion rates from DMSP to DMS, etc. They were optimized to achieve a good agreement between model results and observations of DMS sea surface concentrations [Kloster et al., 2006]. The temperature function $f(T)=\left(1+\frac{1}{\left(T+k_{p t}\right)^{2}}\right)$ gives credit to the observation that the DMSP content in phytoplankton cells increases with decreasing temperatures [Baumann et al., 1994]. $T$ is given in ${ }^{\circ} \mathrm{C}$ and $k_{p t}$, the scaling factor for the temperature dependency, is part of the optimization.

[17] For the degradation of DMS in the ocean, three processes are considered: photooxidation into DMSO $\left(D M S_{U V}\right)$, consumption by bacteria $\left(D M S_{b a c}\right)$, and the DMS flux into the atmosphere $\left(D M S_{f l u x}\right)$. These processes are simulated according to the following equations:

[18] Photooxidation into DMSO: The destruction of DMS by photooxidation to DMSO depends to first order on the solar radiation [Toole and Siegel, 2004; Toole et al., 2004; Shooter and Brimblecombe, 1989; Brimblecombe and Shooter, 1986; Kieber et al., 1996].

$$
D M S_{U V}=k_{l u v} * I_{z} *[D M S]
$$

where $k_{\text {luv }}$ scales the DMS degradation by photooxidation and $I(z)$ denotes the depth-dependent solar radiation. HAMOCC5.1 accounts for the self-shading effect of phytoplankton, i.e., the incoming solar radiation $I_{0}$, taken from the ECHAM5 model, is attenuated by phytoplankton and water in the following way:

$$
I_{z}=I_{0} * e^{-k_{w} * z} * e^{-k_{c h l} * z}
$$

where $k_{w}$ is the light attenuation coefficient for pure water and $k_{c h l}$ for phytoplankton, parameterized as a linear funtion of the chlorophyll concentration [Maier-Reimer et al., 2005].

[19] Bacterial consumption of DMS:

$$
D M S_{b a c}=k_{l b} *(T+3 .) *[D M S] * f([D M S])
$$


$\mathrm{T}$ is in ${ }^{\circ} \mathrm{C}$ and $k_{l b}$ denotes the scaling factor for the consumption by bacteria.

[20] Observations suggest that consumption by bacteria appears to be less efficient in oligotrophic areas with low DMS concentrations [Kiene and Bates, 1990]. We parameterize this variation with a saturation function:

$$
f([D M S])=\left(\frac{[D M S]}{k_{c b}+[D M S]}\right)
$$

where $k_{c b}$ is set to $10 \mathrm{nmol} / \mathrm{l}$ which ensures an almost linear behavior for low DMS concentrations.

[21] DMS flux into the atmosphere:

$$
D M S_{f l u x}=k_{\text {sea-air }} *[D M S]
$$

$k_{\text {sea-air }}$ denotes the sea-air exchange rate. We choose the formulation after Wanninkhof [1992], depending quadratically on the $10 \mathrm{~m}$ wind speed.

[22] The scaling factors $\left(k_{p s i}, k_{p c c}, k_{p t}, k_{l u v}, k_{l b}\right)$ are derived from an optimization procedure by minimizing the difference between simulated DMS sea surface concentrations and the more than 15,000 DMS sea surface concentration measurements reported in the Kettle and Andreae [2000] database. With the resulting parameters we are able to simulate global DMS sea surface concentrations that show a realistic distribution pattern compared to the available DMS sea surface concentration measurements. The model captures the seasonal variations with high DMS sea surface concentrations in the high latitudes in the summer hemispheres [Kloster et al., 2006]. However, up to now it is not possible to find global constraints for the simulated DMS consumption and production processes. The simulated dominant DMS removal process for present day conditions is consumption by bacteria ( $83 \%$ on the global annual mean). The flux into the atmosphere and the photooxidation into DMSO are degradation processes of minor importance ( $8 \%$ and $10 \%$ on the global annual mean, respectively) [Kloster et al., 2006]. This is consistent with the few observations of the consumption processes in the ocean. Archer et al. [2002] found a DMS flux equivalent to $10 \%$ of the DMS production for the northern North Sea. Bacterial consumption accounted for the majority of the DMS removal $(62-82 \%$ for surface levels and $98 \%$ for subsurface levels). Similar findings are reported for the Eastern Tropical Pacific, where measurements show a 3 to 430 times faster removal of DMS by biological consumption than through the DMS flux into the atmosphere [Kiene and Bates, 1990] and for the North East Pacific, where biological consumption accounted for $63 \%$ of the total DMS consumption and the DMS flux into the atmosphere accounted for only a small fraction (1\%) of the DMS loss [Bates et al., 1994]. The fact that the optimization process leads to DMS consumption and production processes that are consistent in the relative magnitude with the few observations available gives us some confidence to apply this parameterization for a long-term climate simulation.

\section{Results}

[23] To separate the climate change signal from the interannual variability we analyse the difference between the mean state of two 30 year periods. We choose the periods 1861-1890 (19c) for preindustrial conditions and the period 2061-2090 (21c) for future conditions. We consider three aspects: First, we analyse changes in physical quantities affecting the biological production in the ocean and hence DMS sea surface concentrations and DMS emissions into the atmosphere. Second, we investigate the response of DMS sea surface concentrations and the DMS flux into the atmosphere to global warming. Third, we assess the resulting changes of DMS concentrations in the atmosphere. Finally, we summarize the findings by relating the observed changes to each other. Results are presented in terms of differences between future $(21 \mathrm{c})$ and preindustrial conditions (19c). Following Roeckner et al. [2006], we test the significance of the differences by applying a nonparametric test, as the usual parametric Student's t test is only applicable for normal distributed parameters. This nonparametric test is described in more detail in the auxiliary material.

\subsection{Changes in the Physical Quantities Affecting the Biological Production}

[24] Detailed descriptions of the atmospheric and oceanic physical mean state and the response to the global warming are presented elsewhere (e.g. Roeckner et al. [2006] focusing on changes in the atmosphere, Stier et al. [2006] focusing on the evolution of the microphysical aerosol system, J. J. Jungclaus et al. (manuscript in preparation, 2006) focusing on the change in the ocean circulation). Here we summarize the physical changes most relevant to future DMS sea surface concentrations and to the DMS flux into the atmosphere.

[25] The transient evolution of the deviation of the global mean air and sea surface temperature and observed global mean temperature from the mean state 1961-1990 are shown in Figure 1. The warming signal observed since the late 19th century is well captured by the simulation. In 2100 , the global mean $2 \mathrm{~m}$ air temperature is predicted to rise by $3.6^{\circ} \mathrm{C}$ compared to the mean state averaged over the period 1961-1990. The global mean sea surface temperature mirrors the rise in the global mean $2 \mathrm{~m}$ temperature. The pattern of the sea surface temperature change shows the strongest warming, between $19 \mathrm{c}$ and $21 \mathrm{c}$ around $4^{\circ} \mathrm{C}$, in the North Pacific and a minimum in the Southern Ocean and in the North Atlantic (due to high ocean heat uptake in areas of deep ocean mixing, see Figure S1 in the auxiliary material). Similar global warming patterns are evident in previous global climate change studies [e.g., Cubasch et al., 2001; Manabe, 1998]. The warming of the atmosphere and ocean surface causes a melting of the sea ice. The melting accelerates during the first half of the 21th century. In 21c, the annual mean sea ice areal coverage has declined by $44 \%$ around Antarctica compared to the initial state in 19c; the decline in the Arctic is even higher $(-50 \%)$. In both hemispheres the summer season shows the strongest decline. Around Antarctica the sea ice coverage is reduced by $70 \%$. The summer season in the Arctic is almost ice free $(-98 \%)$. This has a direct impact on the DMS flux which is inhibited in regions covered by sea ice.

[26] The increase in the sea surface temperature and freshwater flux in the high latitudes induced by stronger rainfall (not shown) cause an overall reduction of the 


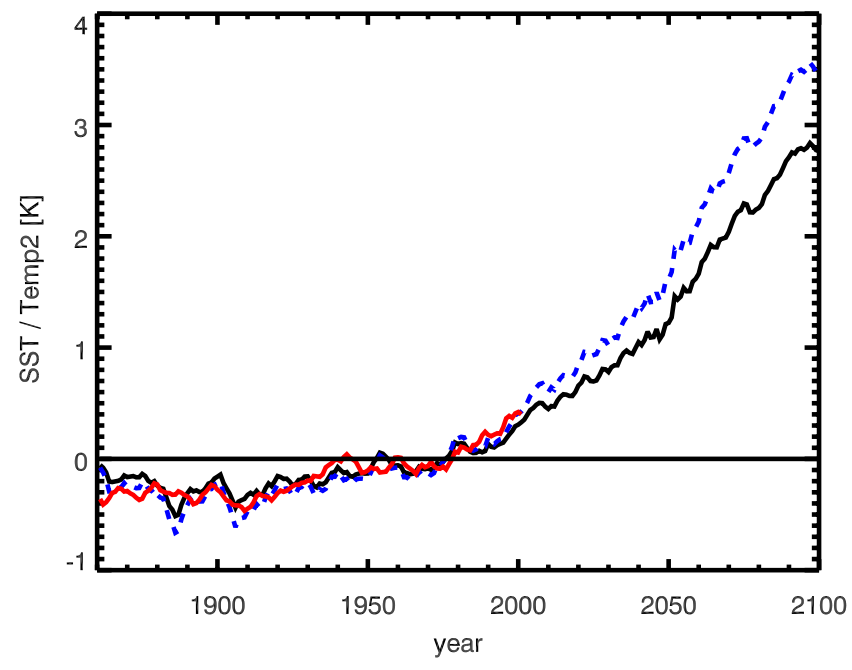

Figure 1. Temporal evolution of the deviation of the annual mean SST (solid black), annual mean $2 \mathrm{~m}$ temperature (dashed blue) and observed annual mean temperatures (red line) from the mean state of 1960-1990 smoothed using a 5-year running mean. Observations are from P. D. Jones et al.: Global and hemispheric temperature anomalies - land and marine instrumental records, available at http://cdiac. ornl.gov/trends/temp/jonescru/jones.html.

surface water density consequently enhancing the ocean stratification. The impact of increased stratification is reflected in the simulated mixed layer depth (MLD). The MLD is defined as the shallowest depth at which water density exceeds its surface value by $0.125 \mathrm{~kg} / \mathrm{m}^{3}$. The maximum MLD, defined as the deepest MLD of the year, decreases in most parts of the ocean (Figure 2a). The decline is strongest where the MLD is deep, for instance in the Southern Ocean and the North Atlantic. Only a few regions show an increase in the MLD. The shoaling of the maximum MLD is evident in most AOGMCs under global warming [e.g., Sarmiento et al., 2004; Manabe, 1998] and is accompanied by a reduction in the Atlantic meridional overturning circulation (19c: $22 \mathrm{~Sv} ; 21 \mathrm{c}: 16 \mathrm{~Sv})$. Changes in the maximum MLD greatly impact the vertical flux of nutrients into the surface ocean waters, stimulating or suppressing surface biological production [e.g., Lequere et al., 2003; Bopp et al., 2001; Sarmiento et al., 2004] and therefore influence DMS production.

[27] The change pattern of the minimum MLD (Figure 2b) reflects the changes in the $10 \mathrm{~m}$ wind speed (see Figure S1b in the auxiliary material). Under warmer climate conditions the $10 \mathrm{~m}$ wind speed increases most noticeably in the central equatorial Pacific and the southern high latitudes. The increase in the southern high latitudes combined with a decrease around $40^{\circ} \mathrm{S}$ is associated with a poleward shift of the storm tracks. This shift has also been observed in other global warming simulations and is related to changes in the zonal SST gradient of the Southern Hemisphere [e.g., Bengtsson et al., 2005; Yin, 2005]. The southward shift of the storm track region leads to the simulated increase in the minimum MLD south of $50^{\circ} \mathrm{S}$ accompanied by a reduction between $40^{\circ}$ and $50^{\circ} \mathrm{S}$. Changes in the minimum MLD become important for the marine biology and thus for the DMS prodution in regions where the primary production is predominantly light limited, such as in the Southern Ocean [e.g., Boyd, 2002a].

\subsection{Response of DMS Sea Surface Concentrations and DMS Flux to Climate Change}

[28] The DMS sea surface concentration is controlled by the DMS production, DMS degradation, DMS emission and transport in the ocean. DMS production depends on the phytoplankton functional group and is parameterized as a function of the export of calcium carbonate and silicate. The export itself is driven by the changes in the total biological production which is influenced by the availability of nutrients, solar radiation, and, to a lesser extent, temperature [Lequere et al., 2003; Bopp et al., 2001]. Before we discuss the changes in the DMS production and degradation, we investigate changes in the driving factors of biological production and export in more detail.

\subsubsection{Changes in the Nutrient Distribution}

[29] Limiting nutrients considered in HAMOCC5.1 are phosphate, nitrate, and iron. In general, the global warming induced stratification in the ocean reduces the vertical transport of nutrients into the surface layers and subsequently the nutrient's surface concentrations. The global annual mean surface concentration of phosphate in $21 \mathrm{c}$ is reduced by $6 \%$ compared to $19 \mathrm{c}$. The reduction for the nitrate surface concentration is of similar magnitude. The iron surface concentration is reduced by about $3 \%$.

[30] The iron surface concentration depends, besides on the mixing into the surface layers, on the dust deposition onto the ocean surface. The explicitly simulated dust deposition increases by $6 \%$ between the periods $19 \mathrm{c}$ and $21 \mathrm{c}$. This increase is predominantly caused by higher dust emissions due to higher wind speeds in the Saharan northwestern source region and subsequent higher dust deposition into the equatorial Atlantic (not shown). This partly counteracts the reduction in sea surface iron through the shoaling of the MLD. However, as the changes in the dust deposition are largest in the equatorial Atlantic where the primary production is not limited by iron [Aumont et al., 2003], we conclude that the overall impact on the biological production and the DMS production in our simulation is only of minor importance.

[31] Surface silicate is reduced by $8 \%$ in the $21 \mathrm{c}$ period compared to $19 \mathrm{c}$. The stronger reduction of silicate compared to nitrate and phosphate is caused by the different prescribed vertical penetration profiles. Generally, maximum silicate concentrations are at deeper levels than phosphate and nitrate maxima. Therefore, a reduction of the vertical mixing in areas of deep mixing has a stronger effect on silicate than on phosphate or nitrate.

[32] The phosphate surface concentration for the $19 \mathrm{c}$ period together with the change pattern between 19c and 21c is shown in Figure 3a. Compared to observations, the present setup of HAMOCC5.1. clearly overestimates the phosphate surface concentration in the Pacific Ocean, most likely caused by a too strong assumed iron limitation of phytoplankton growth. However, as the DMS parmeterization is optimized with this specific model setup and the iron concentration in the transient climate simulation is not changing significantly, we conclude that the model still 
A

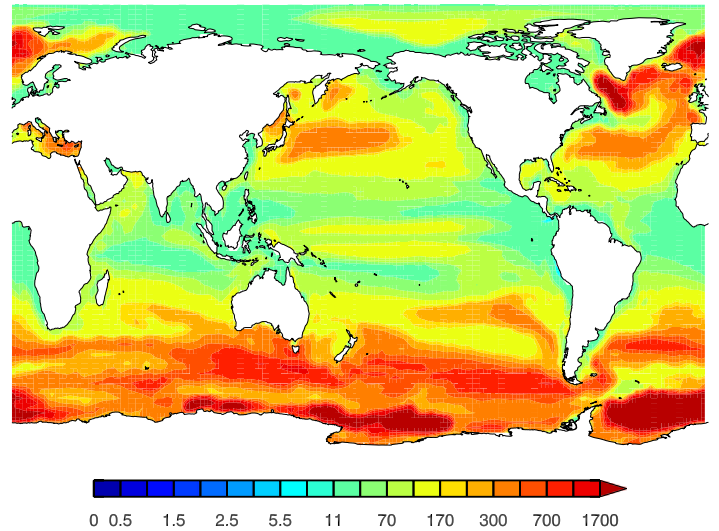

B

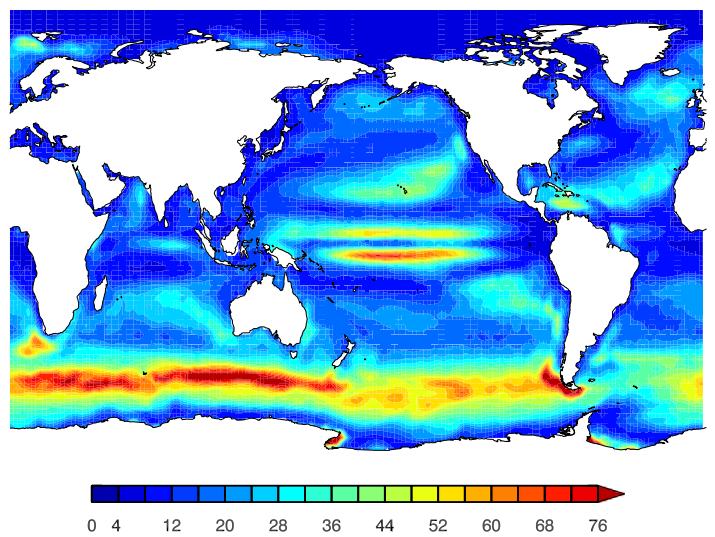

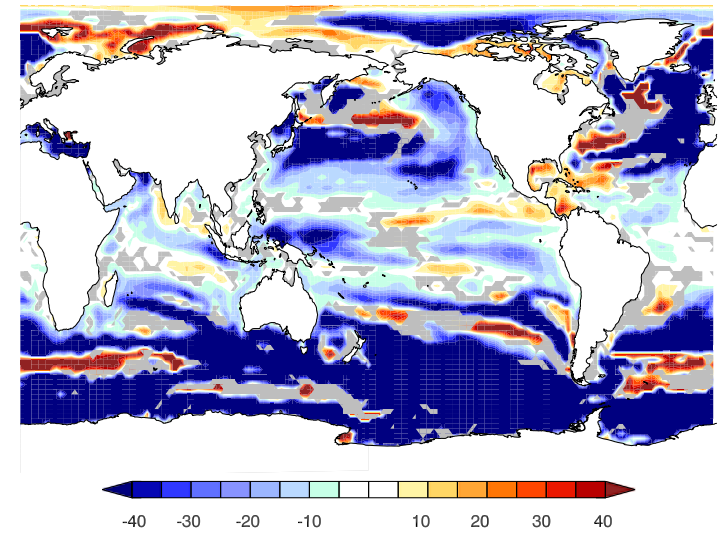

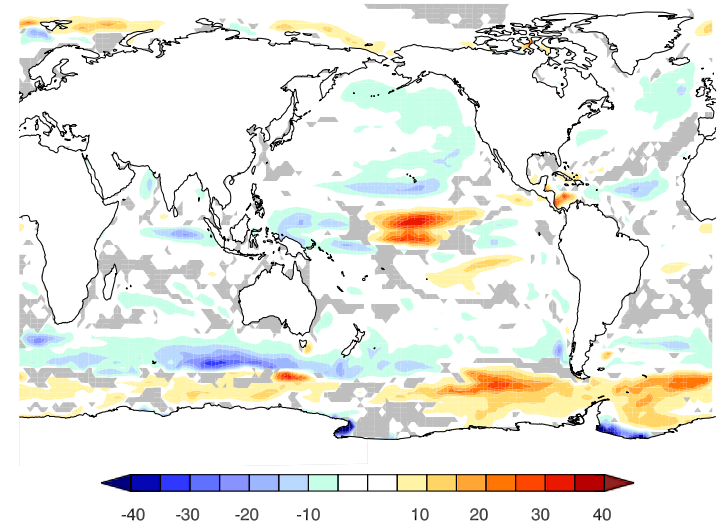

Figure 2. (a) Maximum mixed layer depth of the year in [m]. (b) Minimum mixed layer depth of the year in [m]. (left) Mean values for the period 1861-1890. (right) Changes between the periods 18611890 and 2061-2090 (21c-19c). Grey areas are regions where the changes are below the 95\% significance level.

captures the sensitivity of the DMS production towards global warming induced changes.

[33] Due to the stratification-induced reduced vertical mixing, the Indian and the South Atlantic Ocean show strong decline in the phosphate surface concentration. Higher surface phosphate concentrations in the period 21c compared to $19 \mathrm{c}$ are simulated in the North Atlantic and in the North Pacific corresponding to regions with a deepening of the maximum MLD. The South East Pacific exhibits along the coast of Chile higher phosphate surface concentrations despite a shoaling in the MLD. In this region, the sea surface temperature response to the simulated global warming is also weaker than in other regions (see Figure S1 in the auxiliary material). The region is characterized by an inflow of relatively cold waters from the Antarctic Circumpolar Current accompanied by a strong vertical mixing which reduces the warming signal. The transport of nutrient rich waters from the Southern Ocean into the East Pacific along the coast of Chile ensures a high supply of nutrients. In the period $21 \mathrm{c}$, the model simulates less primary productivity in the Southern Ocean (between $50^{\circ}$ and $60^{\circ} \mathrm{S}$ ) leaving more nutrients in the surface waters compared to the period 19c. This leads to an enhanced flow of nutrients into the South East Pacific and explains the observed increase in the phosphate surface concentration.

\subsubsection{Changes in the Export}

[34] The changes in nutrient surface concentrations have a strong impact on the net primary production and export production. Averaged over the period $19 \mathrm{c}$, the simulated

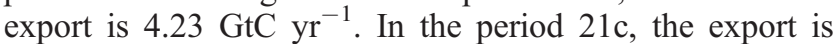
reduced by $12 \%$ and amounts to $3.71 \mathrm{GtC} \mathrm{yr}^{-1}$. Similar findings are reported by Bopp et al. [2001]. Under $2 \times \mathrm{CO}_{2}$ conditions (assuming a $1 \%$ increase per year) compared to present-day conditions they find a reduced export (globally by $-6 \%)$. Our simulated changes in the export are linked to changes in the net primary production $(-8 \%)$, the phytoplankton concentration $(-6 \%)$ and the zooplankton concentration $(-14 \%)$. This is in agreement with simulations performed by Bopp et al. [2001] (net primary production: $-9 \%$, phytoplankton: $-6 \%$, zooplankton: $-9 \%$ ).

[35] Changes of calcium carbonate and silicate export patterns are displayed in Figures $3 b$ and $3 c$. The silicate export declines for most parts of the ocean under warmer climate conditions (on the global annual mean $-16 \%$ between the $19 \mathrm{c}$ and $21 \mathrm{c}$ period). The decrease simulated in the equatorial Atlantic and in the Indian Ocean coincides with reduced surface nutrient concentrations. The reduction in the Southern Ocean (between $50^{\circ}$ and $60^{\circ} \mathrm{S}$ ) matches the difference pattern shown for the minimum MLD (see Figure $2 b$ ), which is enhanced in a warmer climate caused 
A

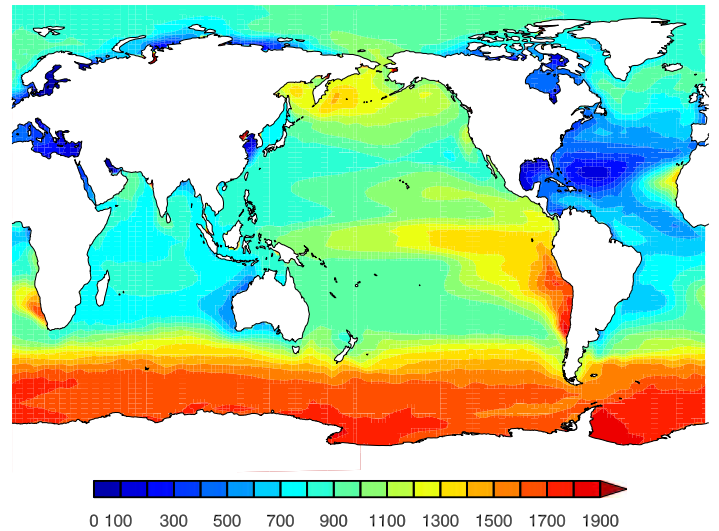

B

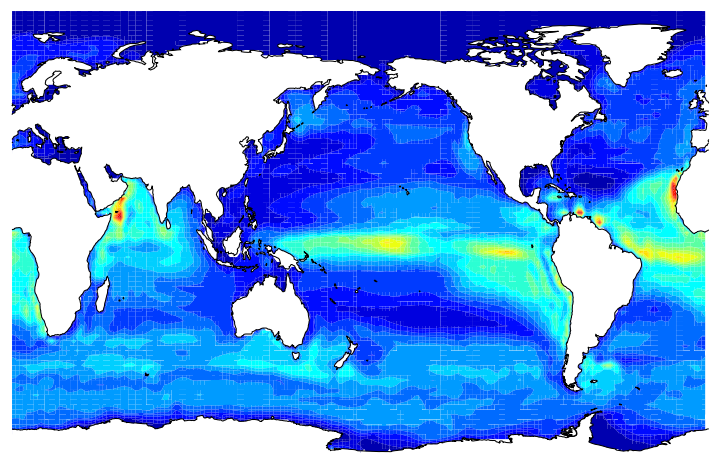

$\begin{array}{lllllllllll}0 & 40 & 120 & 200 & 280 & 360 & 440 & 520 & 600 & 680 & 760\end{array}$

C

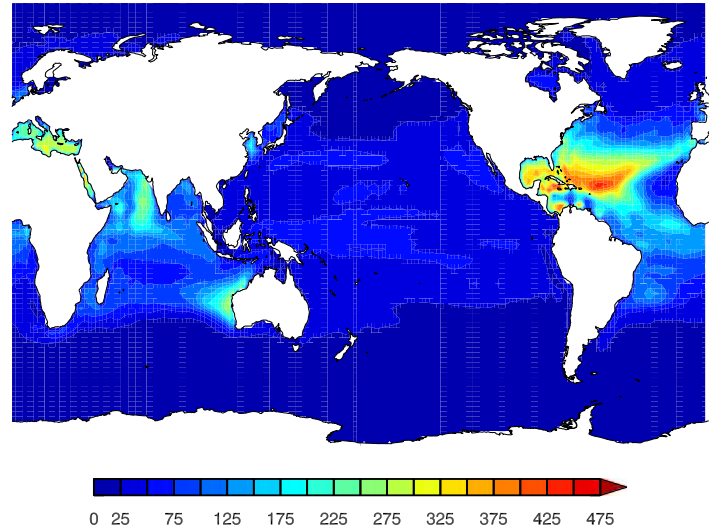

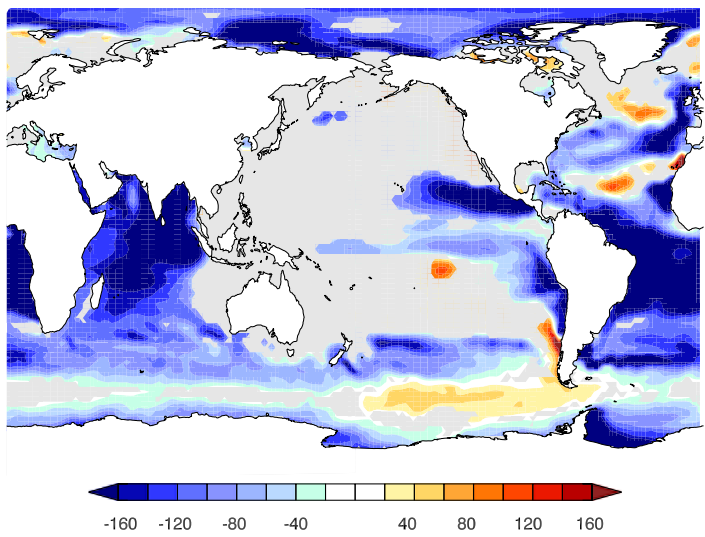
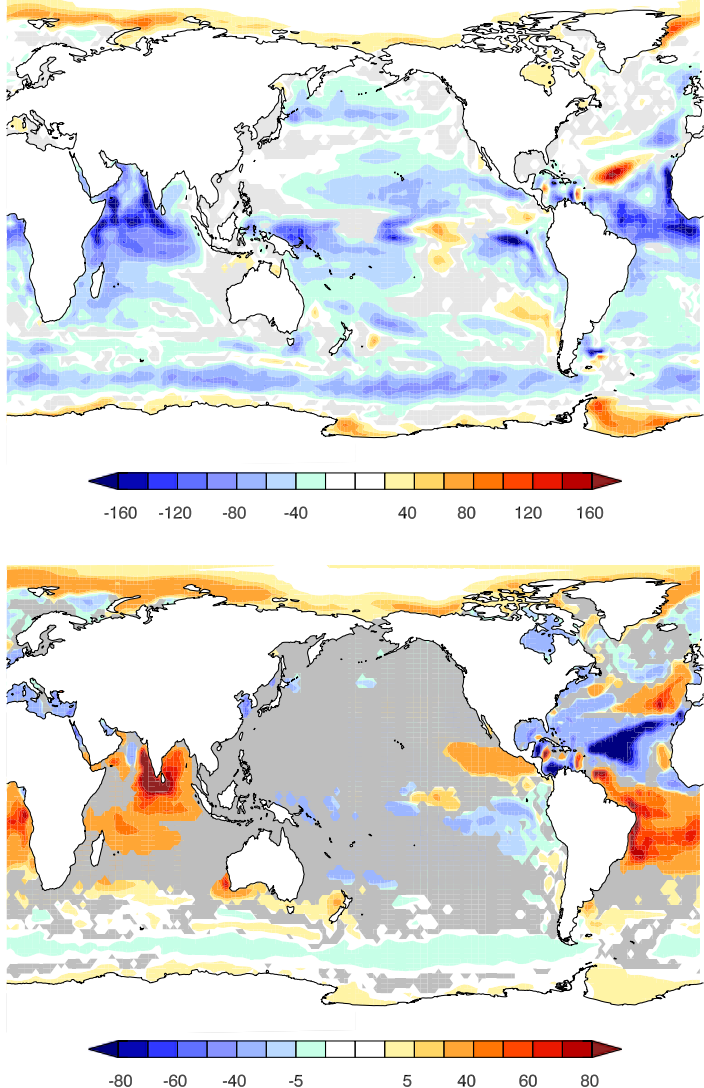

Figure 3. Same as Figure 2. (a) Annual mean phosphate surface concentration in [nmol/1]. (b) Annual mean export of silicate in $\left[\mathrm{mmol} /\left(\mathrm{m}^{2}\right.\right.$ year $\left.)\right]$. (c) Annual mean export of calcium carbonate in $[\mathrm{mmol} /$ $\left(\mathrm{m}^{2}\right.$ year $\left.)\right]$.

by increasing wind speeds in this region. In the Southern Ocean, the primary productivity is light-limited, i.e primary production only takes place in summer when a shallow MLD keeps the phytoplankton in the euphotic zone, where it receives sufficient light for photosynthesis. An increase in the summer time MLD, as simulated for a warmer climate, results in a mixing of phytoplankton into deeper regions where insolation is much lower than in the surface layers, as light is attenuated by the water and by the phytoplankton itself. In addition, the reduced maximum MLD in the Southern Ocean in a warmer climate reduces the nutrient supply. Deep winter mixing still ensures a sufficient supply of nutrients into the surface waters even after a reduction due to global warming. Additionally, we observe a slight decrease in the solar radiative flux at the water surface (up to $10 \mathrm{~W} / \mathrm{m}^{2}$ on the annual mean, not shown) caused by a shift in cloud cover in the zonal band between $50^{\circ}$ and $60^{\circ} \mathrm{S}$. Combining these effects, the light conditions in the Southern Ocean are less favorable for primary production in the $21 \mathrm{c}$ period compared to the $19 \mathrm{c}$ period. This leads to a reduced primary production and subsequently to a reduced export of silicate in the Southern Ocean.

[36] An increase of silicate export is simulated in the high latitudes, in the North Atlantic and in the South East Pacific. In the high latitudes, the reduced sea ice cover increases the available insolation needed for the photosynthesis, which 
A

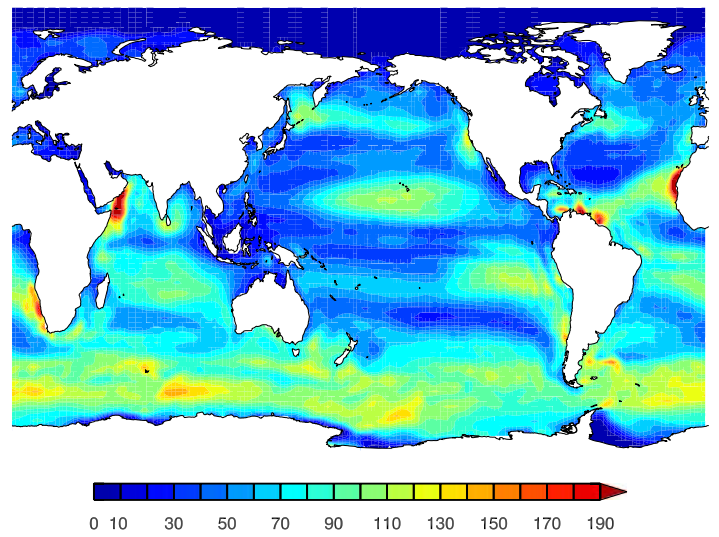

B

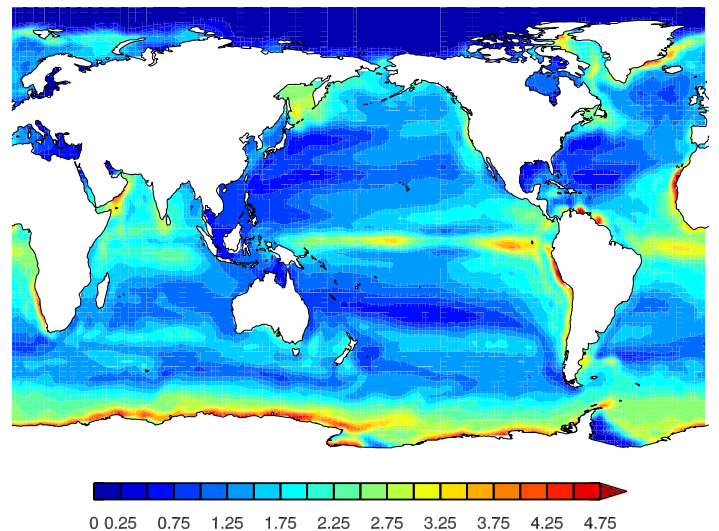

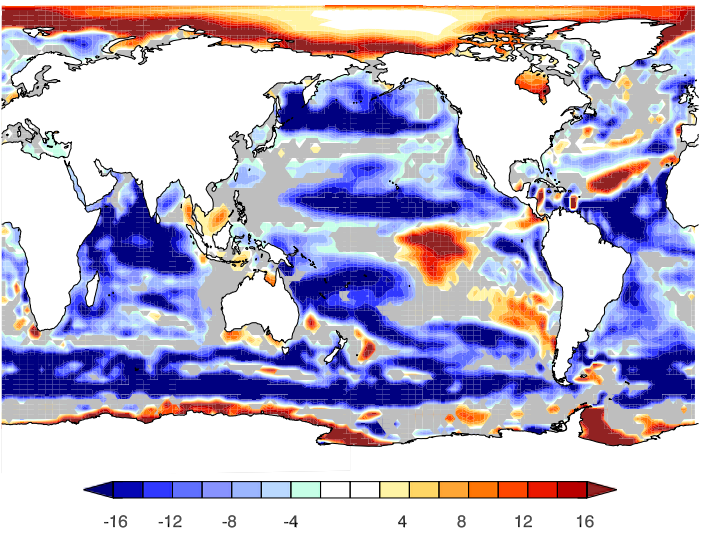

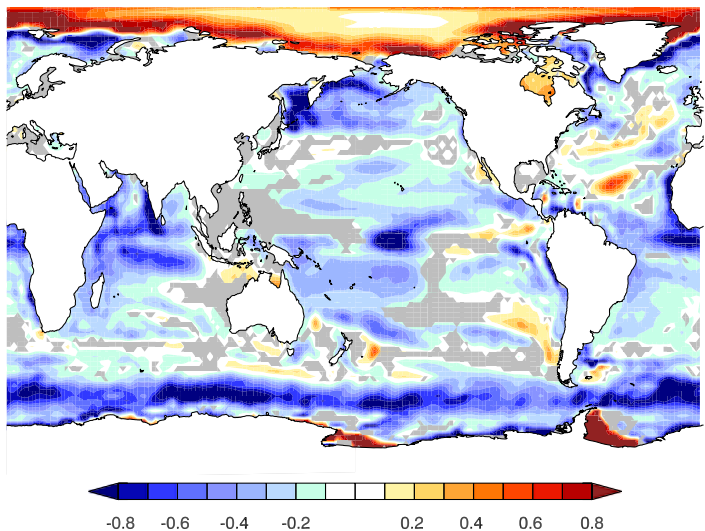

Figure 4. Same as Figure 2. (a) DMS flux into the atmosphere in $\left[\mathrm{mg}(\mathrm{S}) /\left(\mathrm{m}^{2}\right.\right.$ year) $]$; (b) DMS sea surface concentration in $[\mathrm{nmol} / 1]$.

leads to an increase in the phytoplankton productivity and consequently in the export production. In the North Atlantic and in the South East Pacific the simulated nutrient concentrations are higher in a warmer climate as described in the previous chapter. These enhanced concentrations coincide with an increase in the export production owing to higher phytoplankton productivity.

[37] Calcium carbonate export exhibits a different anomaly pattern compared to that of silicate export (see Figures $3 \mathrm{~b}$ and $3 \mathrm{c}$ ). Globally, the export increases by about $1 \%$. The regions with the strongest increase are the Indian Ocean and the South Atlantic where the silicate export shows the strongest decline. This response of calcium carbonate export is caused by the fact that in the model phytoplankton production and hence export production is linked to opal producing phytoplankton as long as silicate is available, after silicate depletion phytoplankton production is linked to calcium carbonate export. The simulated stronger export of calcium carbonate indicates a shift of the phytoplankton species from diatoms towards coccolithophorids in the Indian Ocean and in the South Atlantic.

\subsubsection{Changes in the DMS Production and Degradation Processes and Resulting DMS Sea Surface Concentrations}

[38] As the simulated DMS production relies on the export production of silicate and calcium carbonate with a higher contribution from calciferous material [Keller et al.,
1989] changes in the export production should be reflected in the DMS distrubtions. Therefore, in our simulation the export of calcium carbonate leads to higher DMS production than the export of silicate. However, the shift towards more calcium carbonate export as simulated in the Indian Ocean and the Atlantic Ocean is more than compensated by the overall reduction in the export production in these regions, leading to an overall decrease in the DMS production. Globally, the annual mean DMS production is reduced by $13 \%$ in $21 \mathrm{c}$ compared to $19 \mathrm{c}$. The changes in the DMS removal by photo-oxidation or bacterial consumption are strongly linked to the changes in the DMS production and show a similar spatiotemporal distribution. The photooxidation of DMS to DMSO is reduced by $13 \%$ and the bacterial consumption by $14 \%$. The DMS flux into the atmosphere is reduced as well $(-10 \%)$. This weaker decline of the DMS flux is predominantly caused by a higher sea air exchange rate in the $21 \mathrm{c}$ period compared to the $19 \mathrm{c}$ period $(+4 \%)$. The increase in the sea air exchange rate, depending quadratically on the wind speed, is predominantly caused by an increase in the $10 \mathrm{~m}$ wind speed $(+1 \%)$ and is partly reduced by a reduction of gas solubility at higher sea-water temperatures.

[39] The global pattern of the changes in the DMS flux are displayed in Figure 4a. Similar to the export production, the DMS flux is reduced in most parts of the ocean. The strong decrease between $50^{\circ}$ and $60^{\circ} \mathrm{S}$ in the DMS produc- 
A

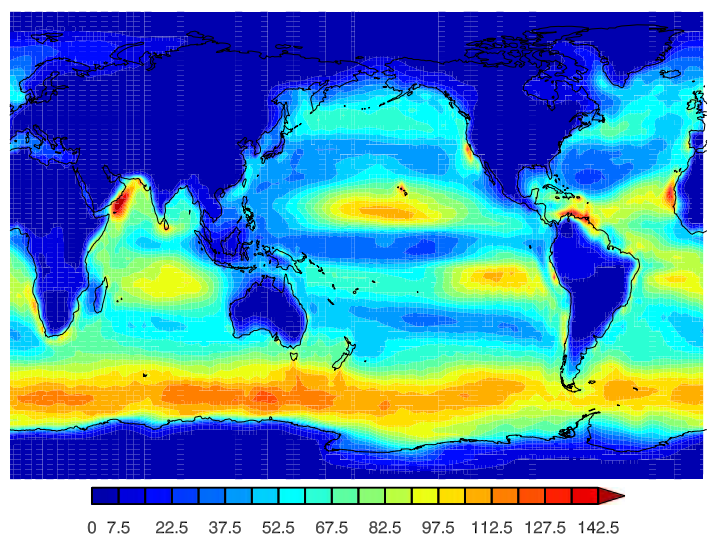

$\mathrm{B}$

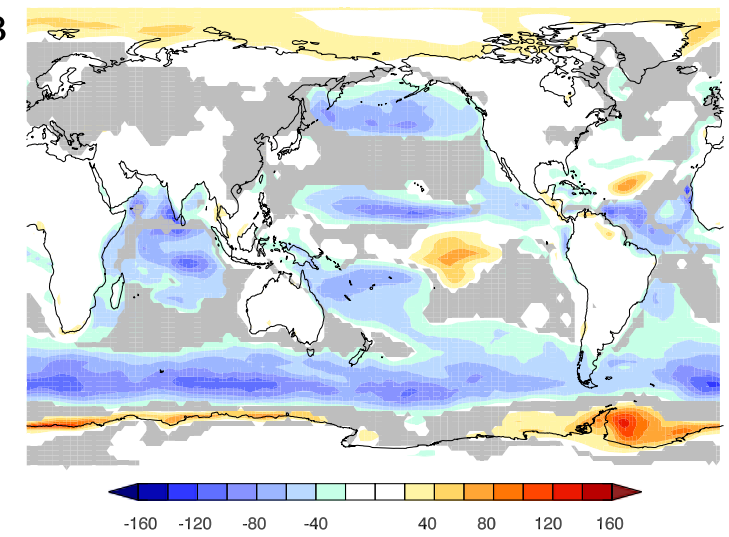

Figure 5. Same as Figure 2. Annual mean DMS burden in the atmosphere in $\left[\mu \mathrm{g} / \mathrm{m}^{2}\right]$.

tion is partly offset by the higher wind speeds simulated for 21c compared to $19 \mathrm{c}$ in this region (see Figure S1b in the auxiliary material). In the South East Pacific and in the North Atlantic, the higher DMS production in the warmer climate combined with high wind speeds in these regions results in a stronger increase in the DMS flux. Additionally, the melting of sea ice allows a DMS flux into the atmosphere in regions that were covered by sea ice in 19c.

[40] How do these changes affect the DMS sea surface concentration? The DMS flux into the atmosphere accounts for only about $8 \%$ of the total DMS sink. The major DMS degradation process is the DMS consumption by bacteria. Therefore, the changes in the DMS sea surface concentrations (Figure $4 \mathrm{~b}$ ) are largely driven by the changes in the DMS production and the DMS consumption by bacteria. In most parts of the ocean, lower DMS sea surface concentrations are simulated in $21 \mathrm{c}$ compared to $19 \mathrm{c}$. Globally, the DMS sea surface concentration is reduced by $7 \%$ in the boreal summer season (June, July and August) and by $15 \%$ in the austral summer season (December, January and February) between $19 \mathrm{c}$ and $21 \mathrm{c}$.

[41] The global mean changes for the different ocean basins are listed for the boreal summer and winter seasons for the periods $19 \mathrm{c}$ and $21 \mathrm{c}$ in Table S2 in the auxiliary material.

\subsection{Response of DMS in the Atmosphere}

[42] The DMS emission from the ocean represents the largest source of DMS in the atmosphere. Emissions from vegetation and soil are only of minor importance $\left(0.3 \mathrm{Tg}(\mathrm{S}) \mathrm{yr}^{-1}\right.$ on the global annual mean [Pham et al., 1995]). Changes in the oceanic DMS emission will therefore have a strong impact on the atmospheric concentration of DMS. DMS oxidation processes considered in the simulation are the reaction with $\mathrm{OH}$ during day-time and with $\mathrm{NO}_{3}$ during night-time. A reduced DMS flux into the atmosphere in a warmer climate causes a reduction of the total DMS oxidation in the atmosphere (globally $-10 \%$ on the annual mean between $19 \mathrm{c}$ and $21 \mathrm{c}$ ). The oxidation of DMS with $\mathrm{NO}_{3}$ is increased in the 21c period compared to the $19 \mathrm{c}$ period $(+3 \%)$, whereas the oxidation with $\mathrm{OH}$ is reduced by $13 \%$. The oxidation with $\mathrm{NO}_{3}$ only becomes prevalent in the polluted regions of the Northern Hemi- sphere during winter when $\mathrm{OH}$ concentrations are low. Enhanced oxidation of DMS due to the reaction with $\mathrm{NO}_{3}$ is therefore most likely caused by an increase in the DMS flux in the North Pacific in the 21c period which amounts to $11 \%$ when averaged over December, January and February (see Table S2 in the auxiliary material).

[43] As the lifetime of DMS is short, the resulting DMS burden shows highest values in regions with strong DMS emissions, most noticeably over the Southern Ocean (Figure 5). The global change pattern of the DMS burden between the period $19 \mathrm{c}$ and $21 \mathrm{c}$ is comparable to changes in the DMS flux (Figure 4a) although the magnitude of the relative changes is smaller. Globally, the DMS burden decreases by $3 \%$ on the annual mean between the period $19 \mathrm{c}$ and $21 \mathrm{c}$.

[44] Figure 6 shows the vertical profile of zonal mean DMS concentrations in the atmosphere for the $19 \mathrm{c}$ period together with the changes between the period $19 \mathrm{c}$ and $21 \mathrm{c}$. DMS in the atmosphere shows a strong increase in the high latitudes coinciding with increasing DMS emissions. Higher DMS concentrations are also found in the lower troposphere in the mid and low latitudes in the $21 \mathrm{c}$ period. This seems to be in contrast to the simulated decrease in the DMS flux into the atmosphere in most of the mid and low latitudes (Figure 4a). The increasing atmospheric DMS concentrations despite decreasing DMS emissions in the mid and low latitudes can be explained by a less efficient DMS oxidation (longer DMS lifetime) in the 21c period. The main oxidation mechanism is the DMS oxidation with $\mathrm{OH}$. $\mathrm{OH}$ distributions exhibit relatively low values at both high latitudes and low altitudes (not shown). This implies that DMS has a relatively long lifetime when emitted at high latitudes or when remaining in the boundary layer in the mid and low latitudes. In the warmer 21c period the vertical transport of DMS in the atmosphere becomes weaker in the mid and low latitudes which keeps DMS longer at lower altitudes, where it is less efficient oxidized compared to higher altitudes. The reduction of the vertical transport in the atmosphere is caused by an overall decrease in the temperature lapse rate in the mid and low latitudes (not shown). This explains the simulated increase in the DMS lifetime $(+7 \%)$ and therefore the weak response of the DMS burden in the atmosphere $(-3 \%)$ to the $-10 \%$ reduction in the DMS emissions. 

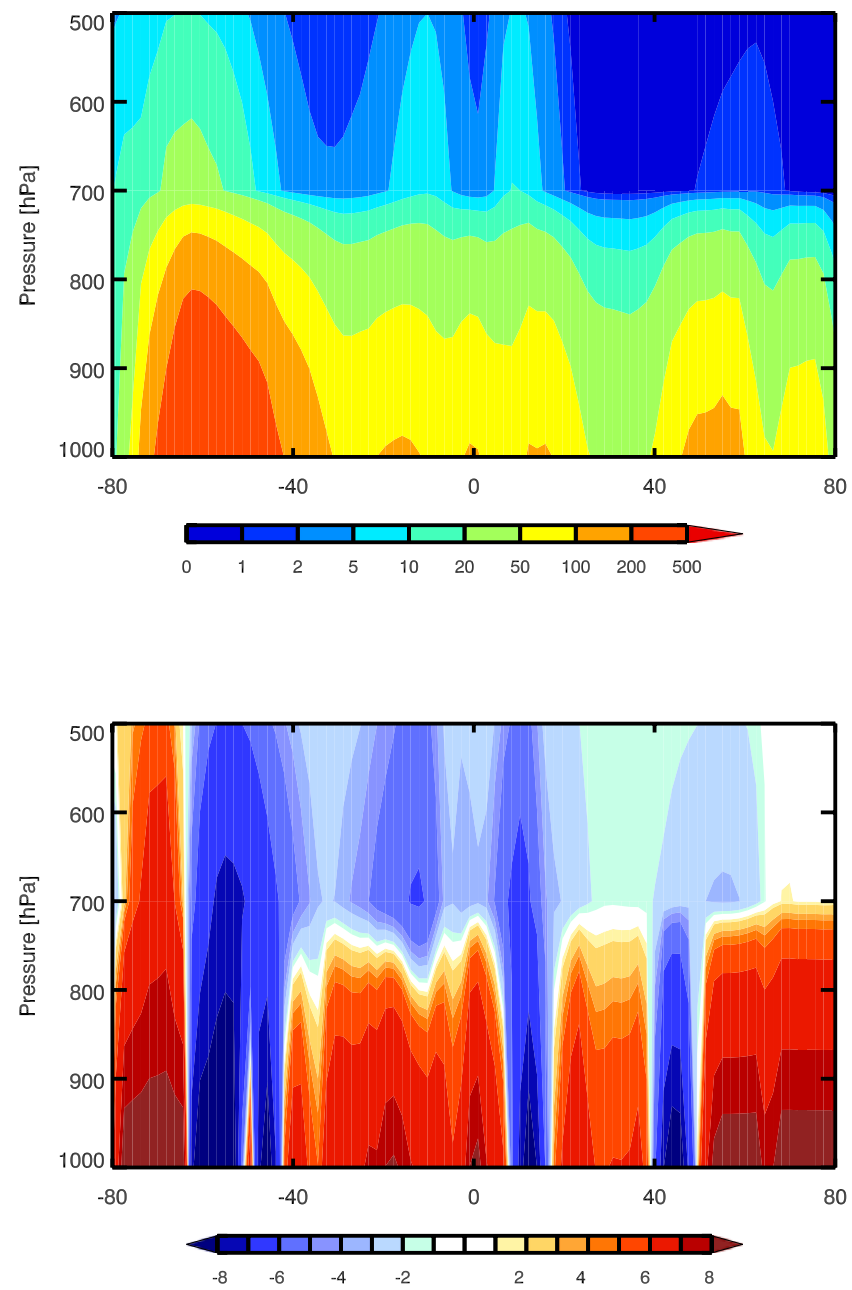

Figure 6. Vertical zonal annual mean profile of DMS in the atmosphere in [pptv]. (top) Mean values for the period 1861-1890. (bottom) Absolute changes between the periods $1861-1890$ and $2061-2890$.

[45] These results are summarized and discussed in terms of zonally averaged percentage changes in the auxiliary material.

\section{Discussion}

[46] Using a coupled ocean-atmosphere model including submodels for the marine biogeochemistry and the microphysical aerosol system, we simulated the evolution of DMS in the ocean and in the atmosphere for the time period from 1860 until 2100 based on the IPCC SRES scenario A1B. The processes for marine DMS production and decay are included in the representation of plankton dynamics in the marine biogeochemistry model HAMOCC5.1 which is embedded in a global ocean general circulation model (MPI-OM). The atmospheric model ECHAM5 is extended by the microphysical aerosol model HAM.

[47] Between the period 1861-1890 and 2061-2090 the global mean sea surface temperature increases by $2.5^{\circ} \mathrm{C}$. The oceanic response to global warming includes increasing sea surface temperatures, retreat of sea ice, and a general increase of ocean stratification. These changes impact on the marine biology and subsequently on the DMS production in the ocean.

[48] Our results indicate a reduction of the global annual mean DMS sea surface concentration and the DMS flux into the atmosphere in a warmer climate. Between the period 1861-1890 and 2061-2090 we found a reduction of around $10 \%$ for both, the DMS flux and the DMS sea surface concentration. The atmospheric DMS concentration is reduced by $3 \%$. The response and underlying mechanisms demonstrate a high degree of regional heterogeneity:

[49] 1. At high northern and southern latitudes the DMS sea surface concentrations show an increase caused by the retreat of sea ice which enhances the insolation in the ocean, the net primary productivity and subsequently the DMS production.

[50] 2. At low and mid latitudes the DMS sea surface concentrations show a decrease $(-10$ to $-20 \%)$ predominantly caused by a stronger stratification of the ocean and a subsequently reduced mixing of nutrients into the euphotic zone leading to a reduced primary production.

[51] 3. In the Southern Ocean between $50^{\circ}$ and $60^{\circ} \mathrm{S}$ we found a strong reduction of the DMS sea surface concentration $(-40 \%)$ caused by an increase in the summer MLD. The deeper summer MLD leads to mixing of phytoplankton into regions where the conditions for photosynthesis are less favorable than in the surface levels due to reduced light availability. The increase in the summer MLD is caused by a shift of the storm tracks towards the south.

[52] 4. In the South East Pacific an increase in the horizontal transport of nutrients into this region, owing to higher surface nutrients concentrations in the Antarctic Circumpolar Current, results in an increase in the DMS sea surface concentration.

[53] 5. Some regions of the North Atlantic show an increase in the DMS sea surface concentration caused by an increase in the winter MLD leading to a higher nutrient transport into the euphotic zone.

[54] 6. The patterns of the DMS flux into the atmosphere are spatially consistent to that of the changes in the DMS sea surface concentrations. Only in few regions the fluxes are partly offset by an increasing sea-air exchange rate.

[55] 7. The DMS concentrations in the atmosphere are less affected by the changes in the DMS flux $(-3 \%$ for the DMS burden). This is due to the fact that DMS in a warmer climate has a longer atmospheric lifetime $(+7 \%)$. Reasons for that are a reduced vertical transport in the $21 \mathrm{c}$ period which keeps mid and low latitude DMS longer in low altitudes where $\mathrm{OH}$ concentrations are lower than in the free troposphere.

[56] Our results do not show a distinct response of the DMS production and hence the DMS sea surface concentrations to changes in the phytoplankton species composition. This is in contrast to the study from Bopp et al. [2004]. For climate conditions equivalent to doubled present-day atmospheric $\mathrm{CO}_{2}$ concentrations, they simulate an increase in the DMS sea surface concentration in the subantarctic Pacific caused by a retreat of diatoms and increase in other species more efficient in producing DMS. This shift results mainly from a decrease in silicate surface concentrations. We also simulate a decrease in silicate surface concentration of similar magnitude in the subantarctic Pacific $\left(10 \mu \mathrm{mol} \mathrm{l}^{-1}\right)$ but additionally, due to the deepening of the summer MLD, 
a decrease in the primary productivity. Therefore, even the reduced silicate surface concentration is still sufficient to supply enough nutrients for diatom growth.

[57] In contrast to the results from Gabric et al. [2004] our simulation shows a distinct decrease of DMS sea surface concentration in the Southern Ocean in a warmer climate in the summer season. Gabric et al. [2004] applied the Simó and Dachs [2002] algorithm, which empirically relates the DMS sea surface concentration to chlorophyll concentration and MLD. For the Southern Ocean, with relatively high chlorophyll concentrations, the DMS sea surface concentration is solely parameterized by the MLD, whereby high DMS sea surface concentrations are associated with a shallow MLD and low DMS sea surface concentrations with a high MLD. In a warmer climate, Gabric et al. [2004] predict an increase of the DMS flux into the atmosphere by a factor up to 11 between 50 and $60^{\circ} \mathrm{S}$, driven by a shallowing of the MLD in a warmer climate. We simulate the same shallowing of the MLD for the winter season. However, the mixing in the Southern Ocean is still deep enough to ensure a sufficient supply of nutrients into the surface layers. Therefore, the phytoplankton production and hence the export and DMS production are not affected.

[58] Modeling, in particular modeling of biological processes, is generally associated with large uncertainties. In the following we address the most uncertain parts in our simulation. While, the formulation of the DMS cycle in the ocean is optimized and tested by using observed present-day DMS sea surface concentrations [Kloster et al., 2006]. It is currently not possible to put global constraints for the DMS consumption and production processes. However, the agreement between the simulated relative magnitude of the specific DMS production and removal processes and regional estimates of the DMS turnover rates led us conclude that the DMS parameterization within HAMOCC5.1 has some skill to simulate the sensitivity of DMS production and thus has skill to reflect in a first attempt the processes in a changing climate.

[59] One shortcoming of our DMS formulation might be the omission of the transformation path through dissolved DMSP (dDMSP). It is difficult to estimate how the results would be affected. As shown within an offline version of HAMOCC5 embedded in the LSG model [Maier-Reimer, 1993] a more detailed DMS parameterization including dDMSP gives an improvement in the DMS sea surface concentration in the equatorial and subpolar regions as compared to a simulation without dDMSP cycling [Six and Maier-Reimer, 2006]. However, phenomena like the high DMS concentrations at Bermuda in summer [Simó and Pedrós-Alió, 1999] are still not reproducible.

[60] Sunda et al. [1990] demonstrated that intercellular phytoplankton production of DMSP and its cleavage to DMS increases as oxidative stressors such as UV-light exposure increase, but the actual intercellular DMSP production rate is still poorly understood. This process is not included in our simulation. UV-light exposures might increase in the future as a result of the shoaling of the MLD, possible leading to an increase in DMS release by phytoplankton. However, recent scenarios show a recovery of stratospheric ozone, leading to a decrease in UV-radiation [IPCC, 2005]. At the same time phytoplankton production will be reduced as a result of limited nutrient supply due to a lower MLD. The net impact on DMS production is not clear. A better understanding of phytoplankton intercellular DMSP content in stressed forced regimes, like high UVexposure, is needed to make a quantitative estimate. We can not rule out that such an effect could lead to higher DMS production rates in a warmer climate.

[61] Dust emissions in our simulation are calculated assuming fixed source areas and vegetation cover representative for the year 2000. An increase in dust emission in the future could enhance phytoplankton growth and therefore DMS production through iron release in regions where phytoplankton growth is under present conditions limited by iron. However, estimates of future changes in dust emissions are highly uncertain (recent estimates range from a modest increase $(+12 \%)$ to a significant decrease $(-60 \%)$ (Tegen et al. [2004] and Mahowald and Luo [2003], respectively). In addition, iron enrichment studies have shown that mainly diatom abundance is enhanced [Boyd et al., 2000], which are generally poor DMS producers. Therefore, it is not possible to estimate the impact on future DMS emissions.

[62] Another critical point is that oxidant fields in the sulfur chemistry scheme are prescribed and kept fixed in this simulation. However, chemical transport models clearly indicate that $\mathrm{OH}$ and $\mathrm{NO}_{3}$, the main oxidants of DMS in the atmosphere, will increase in the future. Pham et al. [2005] showed that the effect of changes in the oxidant fields from 2000 to 2100 assuming the SRES A2 scenario results in a global decrease of the DMS burden by $22 \%$, when atmospheric meteorological conditions are kept constant. However, the SRES A2 scenario is a relatively extreme scenario compared to the SRES A1B scenario applied in this study. We anticipate the SRES A1B scenario would result in smaller changes. However, this would not change our conclusion that the DMS burden is reduced in a warmer climate.

[63] Although a quantitative estimate of the climate feedback of DMS is beyond the scope of this study, the results here suggest that a global warming leads to a reduction of the overall biological production in the ocean and therefore to a decrease in the DMS sea surface concentration, contradicting the negative feedback proposed in the CLAW hypothesis [Charlson et al., 1987]. In the CLAW hypothesis a key factor for a negative feedback is an increase in the DMS sea surface concentration in a warmer climate. However, our simulation indicates the opposite, i.e., decreasing DMS sea surface concentrations in a warmer climate, for the global mean and most of the ocean surface.

[64] The next step is to investigate the impact of sulfate aerosols derived from DMS oxidation in the atmosphere on cloud properties. The prognostic treatment of aerosol size distribution, composition and mixing state in the ECHAM5HAM model allows the explicit simulation of cloud droplet and ice crystal number concentrations. Future work will need assess how changes in the cloud droplets and ice crystal number concentrations caused by changes in the DMS emission impact the radiation balance of the Earth.

[65] Acknowledgments. We would like to acknowledge the support of the German DEKLIM project funded by the German Ministry for Education and Research (BMBF) and the support of the International 
Max Planck Research School for Earth System Modelling. The simulations were done on the HLRE the High Performance Computing System for Earth System Research at the German Climate Computing Center (DKRZ).

\section{References}

Archer, S. D., G. C. Smith, P. D. Nightingale, C. E. Widdicombe, G. A. Tarran, A. P. Rees, and P. H. Burkill (2002), Dynamics of particulate dimethylsulphoniopropionate during a lagrangian experiment in the northern North Sea, Deep Sea Res., 49(15), 2979-2999.

Aumont, O., S. Belviso, and P. Monfray (2002), Dimethylsulfoniopropionate (DMSP) and dimethylsulfide (DMS) sea-surface distributions simulated from a global three-dimensional ocean carbon cycle model, J. Geophys. Res., 107(C4), 3029, doi:10.1029/1999JC000111.

Aumont, O., E. Maier-Reimer, S. Blain, and P. Monfray (2003), An ecosystem model of the global ocean including $\mathrm{Fe}, \mathrm{Si}, \mathrm{P}$ colimitations, Global Biogeochem. Cycles, 17(2), 1060, doi:10.1029/2001GB001745.

Bates, T. S., R. P. Kiene, G. V. Wolfe, P. A. Matrai, F. P. Chavez, K. R. Buck, B. W. Blomquist, and R. L. Cuhel (1994), The cycling of sulfur in surface seawater of the northeast Pacific, J. Geophys. Res., 99(C4), $7835-7843$

Baumann, M. E. M., F. P. Brandini, and R. Staubes (1994), The influence of light and temperature on carbon-specific DMS release by cultures of phaeocystis-antarctica and 3 antarctic diatoms, Mar. Chem., 45(1-2), $129-136$.

Belviso, S., L. Bopp, C. Moulin, J. C. Orr, T. R. Anderson, O. Aumont, S. Chu, S. Elliott, M. E. Maltrud, and R. Simo (2004), Comparison of global climatological maps of sea surface dimethyl sulfide, Global Biogeochem. Cycles, 18, GB3013, doi:10.1029/2003GB002193.

Bengtsson, L., K. I. Hodges, and E. Roeckner (2005), Storm tracks and climate change, J. Clim., 19(15), 3518-3543.

Bopp, L., P. Monfray, O. Aumont, J. L. Dufresne, H. L. Treut, G. Madec, L. Terray, and J. C. Orr (2001), Potential impact of climate change on marine export production, Global Biogeochem. Cycles, 15(1), 81-99.

Bopp, L., O. Aumont, S. Belviso, and P. Monfray (2003), Potential impact of climate change on marine dimethyl sulfide emissions, Tellus, Ser. B., 55(1), 11-22.

Bopp, L., O. Boucher, O. Aumont, S. Belviso, J. L. Dufresne, M. Pham, and P. Monfray (2004), Will marine dimethylsulfide emissions amplify or alleviate global warming? A model study, Can. J. Fish. Aquat. Sci., 61(5), 826-835

Boyd, P. W. (2002a), Environmental factors controlling phytoplankton processes in the Southern Ocean, J. Phycol., 38(5), 844-861.

Boyd, P. W., and S. C. Doney (2002b), Modeling regional responses by marine pelagic ecosystems to global climate change, Geophys. Res. Lett., 29(16), 1806, doi:10.1029/2001GL014130.

Boyd, P. W., et al. (2000), A mesoscale phytoplankton bloom in the polar Southern Ocean stimulated by iron fertilization, Nature, 407, 695-702.

Brimblecombe, P., and D. Shooter (1986), Photooxidation of dimethylsulfide in aqueous-solution, Mar. Chem., 19(4), 343-353.

Charlson, R. J., J. E. Lovelock, M. O. Andreae, and S. G. Warren (1987), Oceanic phytoplankton, atmospheric sulfur, cloud albedo and climate, Nature, 326(6114), 655-661.

Cox, P. M., R. A. Betts, C. D. Jones, S. A. Spall, and I. J. Totterdell (2000), Acceleration of global warming due to carbon-cycle feedbacks in a coupled climate model, Nature, 408(6809), 184-187.

Cubasch, U., G. A. Meehl, G. J. Boer, R. J. Souffer, M. Dix, A. Noda, C. A. Senior, S. Raper, and K. S. Yap (2001), Projection of future climate change, in Climate Change 2001: The Scientific Basis, edited by J. T. Houghton, pp. 527-582, Cambridge Univ. Press, New York.

Denman, K., E. Hofmann, and H. Marchant (1996), Marine biotic response to global environmental change and feedbacks to climate, in Climate Change, pp. 483-516, edited J. T. Houghton, Cambridge Univ. Press, New York.

Gabric, A. J., R. Cropp, T. Hirst, and H. Marchant (2003), The sensitivity of dimethyl sulfide production to simulated climate change in the eastern Antarctic Southern Ocean, Tellus, Ser. B., 55(5), 966-981.

Gabric, A. J., R. Simó, R. A. Cropp, A. C. Hirst, and J. Dachs (2004), Modeling estimates of the global emission of dimethylsulfide under enhanced greenhouse conditions, Global Biogeochem. Cycles, 18, GB2014, doi:10.1029/2003GB002183.

Gauss, M., et al. (2003), Radiative forcing in the 21 st century due to ozone changes in the troposphere and the lower stratosphere, J. Geophys. Res., 108(D9), 4292, doi:10.1029/2002JD002624.

Horowitz, L. W., et al. (2003), A global simulation of tropospheric ozone and related tracers: Description and evaluation of MOZART, version 2, J. Geophys. Res., 108(D24), 4784, doi:10.1029/2002JD002853.

Intergovernmental Panel on Climate Change (IPCC) (2001), Climate Change 2001: The Scientific Basis, edited by J. T. Houghton, 881 pp., Cambridge Univ. Press, New York.
Intergovernmental Panel on Climate Change (IPCC) (2005), Special Report on Safeguarding the Ozone Layer and the Global Climate System: Issues Related to Hydrofluorocarbons and Perfluorocarbon, edited by B. Metz et al., 478 pp., Cambridge Univ. Press, New York.

Johnson, C. E., W. J. Collins, D. S. Stevenson, and R. G. Derwent (1999), Relative roles of climate and emissions changes on future tropospheric oxidant concentrations, J. Geophys. Res., 104(D15), 18,631-18,645.

Joos, F., G. K. Plattner, T. F. Stocker, O. Marchal, and A. Schmittner (1999), Global warming and marine carbon cycle feedbacks an future atmospheric $\mathrm{CO}_{2}$, Science, 284(5413), 464-467.

Keller, M. D., W. K. Bellows, and R. R. L. Guillard (1989), Dimethyl sulfide production in marine phytoplankton, in Biogenic Sulfur in the Enviroment, ACS Symp. Ser, edited by E. Saltzman and W. Cooper, pp. 167-181, Am. Chem. Soc., New Orleans, La.

Kettle, A. J., and M. O. Andreae (2000), Flux of dimethylsulfide from the oceans: A comparison of updated data sets and flux models, J. Geophys. Res., 105(D22), 26,793-26,808.

Kettle, A. J., et al. (1999), A global database of sea surface dimethylsulfide (DMS) measurements and a procedure to predict sea surface DMS as a function of latitude, longitude, and month, Global Biogeochem. Cycles, 13(2), 399-444.

Kieber, D. J., J. F. Jiao, R. P. Kiene, and T. S. Bates (1996), Impact of dimethylsulfide photochemistry on methyl sulfur cycling in the equatorial Pacific Ocean, J. Geophys. Res., 101(C2), 3715-3722.

Kiene, R. P., and T. S. Bates (1990), Biological removal of dimethyl sulfide from sea-water, Nature, 345(6277), 702-705.

Kiene, R. P., L. J. Linn, and J. A. Bruton (2000), New and important roles for DMSP in marine microbial communities, J. Sea Res., 43(3-4), 209224.

Kloster, S., J. Feichter, E. Maier-Reimer, K. D. Six, P. Stier, and P. Wetzel (2006), DMS cycle in the marine ocean-atmosphere system - a global model study, Biogeosciences, 3, 29-51.

Lequere, C. L., O. Aumont, P. Monfray, and J. Orr (2003), Propagation of climatic events on ocean stratification, marine biology, and $\mathrm{CO}_{2}$ : Case studies over the 1979-1999 period, J. Geophys. Res., 108(C12), 3375, doi:10.1029/2001JC000920.

Lochte, K., H. W. Ducklow, M. J. R. Fasham, and C. Stienen (1993), Plankton succession and carbon cycling at $47^{\circ} \mathrm{N}-20^{\circ} \mathrm{W}$ during the JGOFS North-Atlantic bloom experiment, Deep Sea Res., Part II, 40, $91-114$

Mahowald, N., and C. Luo (2003), A less dusty future?, Geophys. Res. Lett., 30(17), 1903, doi:10.1029/2003GL017880.

Maier-Reimer, E. (1993), Geochemical cycles in an ocean general circulation model: Preindustrial tracer distributions, Global Biogeochem. Cycles, 7(3), 645-677.

Maier-Reimer, E., U. Mikolajewicz, and A. Winguth (1996), Future ocean uptake of $\mathrm{CO}_{2}$ : Interaction between ocean circulation and biology, Clim. Dyn., 12, 711-721.

Maier-Reimer, E., I. Kriest, J. Segschneider, and P. Wetzel (2005), The Hamburg Ocean Carbon Cycle Model HAMOCC5.1 - Technical description release 1.1, Rep. Earth Syst. Sci. 14, Max Planck Inst. for Meteorol., Hamburg, Germany. (Available at http://www.mpimet.mpg.de)

Manabe, S. (1998), Study of global warming by GFDL climate models, $A M B I O, 27(3), 182-186$

Marsland, S. J., H. Haak, J. H. Jungclaus, M. Latif, and F. Roske (2003), The Max-Planck-Institute global ocean/sea ice model with orthogonal curvilinear coordinates, Ocean Modell., 5(2), 91-127.

Matear, R. J., and A. C. Hirst (1999), Climate change feedback on the future oceanic $\mathrm{CO}_{2}$ uptake, Tellus, Ser. B., 51(3), 722-733.

Orr, J., et al. (2005), Anthropogenic ocean acidification over the twentyfirst century and its impact on calcifying organisms, Nature, 437(7059), $681-686$.

Pham, M., J. F. Müller, G. P. Brasseur, C. Granier, and G. Megie (1995), A three-dimensional study of the tropospheric sulfur cycle, J. Geophys. Res., 100(D12), 26,061-26,092.

Pham, M., O. Boucher, and D. Hauglustaine (2005), Changes in atmospheric sulfur burdens and concentrations and resulting radiative forcings under IPCCSRES emission scenarios for 1990-2100, J. Geophys. Res., 110, D06112, doi:10.1029/2004JD005125.

Plattner, G. K., F. Joos, T. F. Stocker, and O. Marchal (2001), Feedback mechanisms and sensitivities of ocean carbon uptake under global warming, Tellus, Ser. B., 53(5), 564-592.

Roeckner, E., et al. (2003), The atmospheric general cirulation model ECHAM5. Part I: Model description, Rep. 349, Max Planck Inst. for Meteorol., Hamburg, Germany. (Available at http://www.mpimet.mpg.de) Roeckner, E., P. Stier, J. Feichter, S. Kloster, M. Esch, and I. Fischer-Bruns (2006), Impact of carbonaceous aerosol forcing on regional climate change, Clim. Dyn., 27(6), 553-571.

Sarmiento, J. L., and T. M. C. Hughes (1999), Anthropogenic $\mathrm{CO}_{2}$ uptake in a warming ocean, Tellus, Ser. B., 51(2), 560-561. 
Sarmiento, J. L., and C. Lequere (1996), Oceanic carbon dioxide uptake in a model of century-scale global warming, Science, 274(5291), 13461350.

Sarmiento, J. L., et al. (2004), Response of ocean ecosystems to climate warming, Global Biogeochem. Cycles, 18, GB3003, doi:10.1029/ 2003 GB002134.

Schulz, M., G. de Leeuw, and Y. Balkanski (2004), Sea salt aerosol source functions and emissions, in Emission of Atmospheric Trace Compounds, edited by C. Granier, P. Artaxo, and C. Reeves.

Shaw, G. E. (1983), Bio-controlled thermostasis involving the sulfur cycle, Clim. Change, 5(3), 297-303.

Shooter, D., and P. Brimblecombe (1989), Dimethylsulfide oxidation in the ocean, Deep Sea Res., Part A, 36(4), 577-585.

Simó, R. (2004), From cells to globe: Approaching the dynamics of DMS(P) in the ocean at multiple scales, Can. J. Fish. Aquat. Sci., 61, $673-684$.

Simó, R., and J. Dachs (2002), Global ocean emission of dimethylsulfide predicted from biogeophysical data, Global Biogeochem. Cycles, 16(4), 1018, doi:10.1029/2001GB001829.

Simó, R., and C. Pedrós-Alió (1999), Role of vertical mixing in controlling the oceanic production of dimethyl sulphide, Nature, 402, 396-399.

Six, K. D., and E. Maier-Reimer (2006), What controls the oceanic dimethylsulfide (DMS) cycle? A modeling approach, Global Biogeochem. Cycles, 20, GB4011, doi:10.1029/2005GB002674.

Stier, P., et al. (2005), The aerosol-climate model ECHAM5-HAM, Atmos. Chem. Phys., 5, 1125-1156.

Stier, P., J. Feichter, E. Roeckner, S. Kloster, and M. Esch (2006), The evolution of the global aerosol system in a transient climate simulation from 1860 to 2100, Atmos. Chem. Phys., 6, 3059-3076.

Sunda, W., D. J. Kieber, R. P. Kiene, and S. Huntsman (1990), An antioxidant function for DMSP and DMS in marine algae, Nature, 418, $317-$ 320
Tegen, I., S. P. Harrison, K. Kohfeld, I. C. Prentice, M. Coe, and M. Heimann (2002), Impact of vegetation and preferential source areas on global dust aerosol: Results from a model study, J. Geophys. Res., 107(D21), 4576 , doi:10.1029/2001JD000963.

Tegen, I., M. Werner, S. P. Harrison, and K. E. Kohfeld (2004), Relative importance of climate and land use in determining present and future global soil dust emission, Geophys. Res. Lett., 31, L05105, doi:10.1029/2003GL019216.

Toole, D. A., and D. Siegel (2004), Light-driven cycling of dimethylsulfide (DMS) in the Sargasso Sea: closing the loop, Geophys. Res. Lett., 31, L09308, doi:10.1029/2004GL019581.

Toole, D. A., D. J. Kieber, R. P. Kiene, E. M. White, J. Bisgrove, and D. A del Valle (2004), High dimethylsulfide photolysis rates in nitrate-rich antarctic waters, Geophys. Res. Lett., 31, L11307, doi:10.1029/ 2004GL019863.

Valcke, S., A. Caubel, D. Declat, and L. Terray (2003), OASIS ocean atmosphere sea ice soil users's guide, Tech Rep. TR/CMGC/03/69, CERFACS, Toulouse, France.

Wanninkhof, R. (1992), Relationship between wind speed and gas exchange over the ocean, J. Geophys. Res., 97(C5), 7373-7382.

Yin, J. H. (2005), A consistent poleward shift of the storm tracks in simulations of 21 st century climate, Geophys. Res. Lett., 32, L18701, doi:10.1029/2005GL023684.

M. Esch, J. Feichter, E. Maier-Reimer, E. Roeckner, K. D. Six, and P. Wetzel, Max Planck Institute for Meteorology, D-20146 Hamburg, Germany.

S. Kloster, JRC-IES, Via Enrico Fermi, 21020 Ispra (Va), Italy. (kloster@dkrz.de)

P. Stier, Department of Environmental Science and Engineering, California Institute of Technology, Pasadena, CA 91125, USA. 